\title{
Rezeke hepatosellüler karsinomalı sirotik hastada nadir üst GiS kanama sebebi: Tümör nüksüne bağlı duodenum invazyonu
}

\author{
A rare cause of upper gastrointestinal bleeding in patients with cirrhosis and resected hepatocellular \\ carcinoma: Recurrent tumor invasion into the duodenum
}

Nalan Gülşen ÜNAL ${ }^{1}$, Nevin ORUÇ ${ }^{1}$ Ömer ÖZÜTEMIZ1 , Başak DOĞANAVŞARGILL ${ }^{2}$, Oktay TEKEŞİN ${ }^{1}$

Ege Üniversitesi Tip Fakültesi, ${ }^{1}$ Namık Kemal Menteș Gastroenteroloji Bilim Dalı, ${ }^{2}$ Patoloji Anabilim Dalı, Izmir

Hepatosellüler karsinoma sirotik karaciğerde en sık görülen tümördür. Bu hastalarda üst gastrointestinal sistem kanamalarnnı en sik nedeni portal hipertansiyona sekonder gelisen varis kanamalarıdır. Gastrointestinal trakta tümör invazyonuna bağll kanama özellikle hepatosellüler karsinoma rezeke vakalarda çok seyrektir. Burada hepatosellüler karsinoma nedeniyle karaciğer rezeksiyonu uygulanmış, tümör nüksünün duodenum invazyonu bağlı masif hematemezle başvuran olgu sunulmuştur.

Anahtar kelimeler: Hepatosellüler karsinoma, gastrointestinal kanama, duodenum invazyonu

\section{GİRİş}

Hepatosellüler karsinoma (HCC) tüm dünyada en yaygın tümörlerden birisidir (1). Sirotik karaciğerde ise en sık görülen tümördür. Günümüz teknolojisinde HCC tedavisinde, iyi seçilmiş vakalarda rezeksiyon ile 5 yıllık sağkalım \%70 civarındadır.

Sirotik hastaların \%25-40'inda portal hipertansiyona sekonder özofagus ve gastrik varis kanaması görülmekte (2) ve yaklaşı \%30 mortalite ile seyretmektedir (3). HCC'nin daha çok portal ven yoluyla hematojenik yayılım gösterdiği bilinmekte-

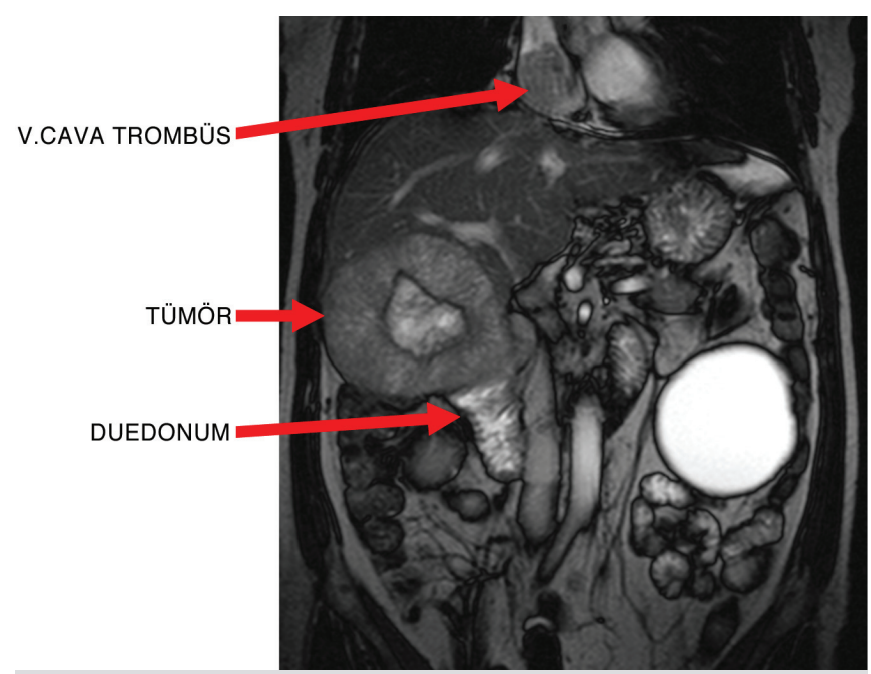

Resim 1. Bilgisayarlı tomografide T2 ağırlıklı koronal imajda duodenuma invaze HCC görünümü
Hepatocellular carcinoma is the most common tumor in cirrhotic patients. The major cause of upper gastrointestinal bleeding in these patients is variceal bleeding secondary to portal hypertension. Bleeding from tumor invasion into the gastrointestinal tract is very rare, especially in hepatocellular carcinoma resected patients. We describe herein a resected hepatocellular carcinoma case who presented with massive hematemesis due to duodenal invasion of tumor recurrence.

Key words: Hepatocellular carcinoma, gastrointestinal bleeding, duodenum invasion

dir. HCC’ye bağll gastrointestinal sistem (GIS) tümör invazyonu çok seyrek olup, yaklaşık \%0,5 ve \%2 oranında bildirilmiştir $(4,5)$ ve kötü prognozla ilişkili bulunmuştur. Tümör invazyonuna bağlı GİS kanaması ise bu orandan daha düşük olup literatürde vaka sunumları şeklindedir. HCC invazyonuna bağlı GIS kanaması ölümcül seyredebilir. Tedavide ise bazı hastalarda cerrahinin mi yoksa kemoembolizasyon tedavisinin mi en iyi seçenek olduğu hala tartışılmaktadır.

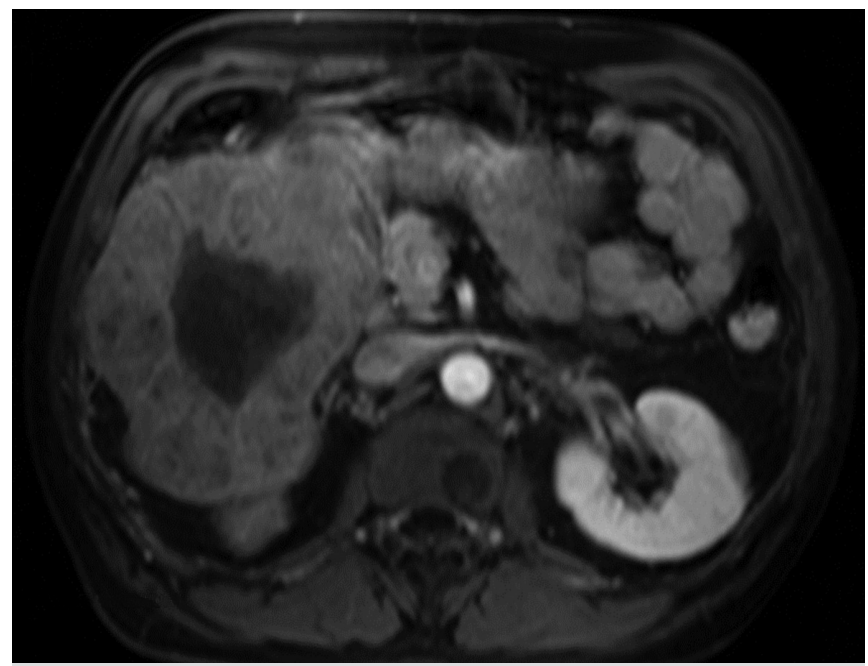

Resim 2. Bilgisayarlı tomografide postkontrast Tl transvers sekansta HCC görünümü

letișim: Nalan Gülșen ÜNAL Ege Üniversitesi Tıp Fakültesi Namık Kemal Menteş Gastroenteroloji Bilim Dalı, Izmir, Türkiye • Tel: + 902323881969 Faks: + 902323881969 • E-mail: drnalanunal@gmail.com Geliș Tarihi: 22.02.2011 Kabul Tarihi: 26.03.2011 


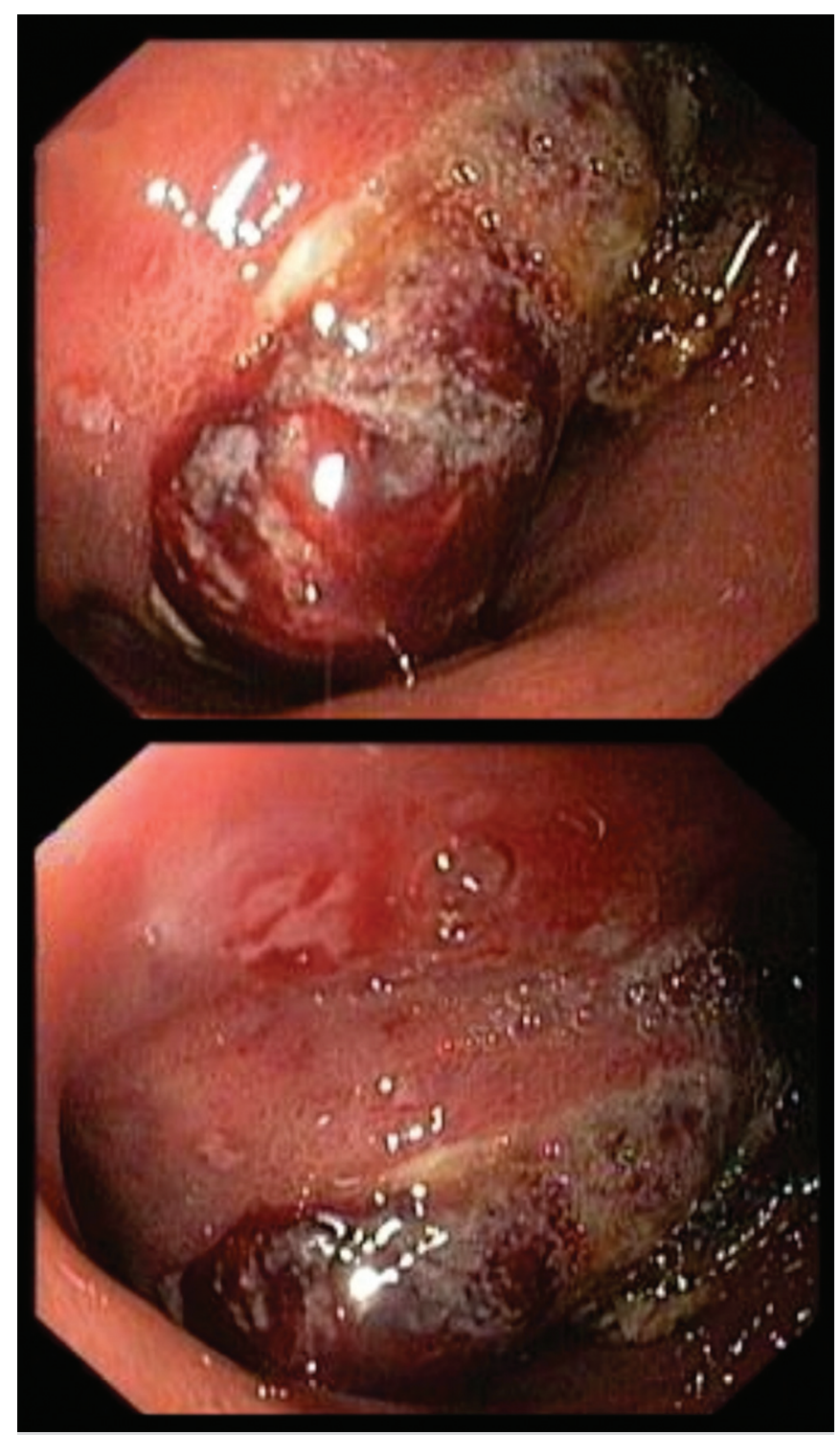

Resim 3-4. Üst GIS endoskopisinde; bulbus ön duvar yönünde HCC duodenum invazyonuna bağlı ülsere, hemorajik kitle görünümü

\section{OLGU SUNUMU}

Kronik hepatit B'ye bağlı karaciğer sirozu tanısı ile takip edilen ve iki yıl önce HCC tanısı ile karaciğerden tümör rezeksiyonu öyküsü mevcut, 54 yaşında erkek hastanın, iki yıllık düzensiz takip sonrası yapılan kontrolünde; serum alfa-fetoprotein: 1280 mg/dl saptanması nedeniyle nüks HCC düşünülerek çekilen batın tomografisinde; karaciğerde özellikle segment 6'dan egzofitik uzanım gösteren en büyükleri yaklaşık $11 \mathrm{~cm}$ çapında, multisentrik HCC ile uyumlu lezyonlar saptanmıştır (Resim 1-2). Yapılan tetkiklerinde; AST: 25 IU/L, ALT: 24 IU/L, albumin: 4,3 gr/dl, total bilirubin: $1,1 \mathrm{mg} / \mathrm{dl}$, protrombin zamanı: 14,1 sn, INR: 1,1, lökosit: $5200 / \mathrm{mm}^{3}$, hemoglobin: 12 gr/dl, hematokrit: \%37, trombosit: 148.000/mm³ bulunmuştur. Medikal onkoloji tarafından kemoterapi amaçlı hospitalize edilen hastanın kemoterapi öncesi masif hemate- mez nedeniyle yapilan üst GIS endoskopisinde; bulbus ön duvar yönünde çapı yaklaşık 3 cm'e ulaşan üzeri ülsere, hemorajik kitle lezyonu izlenmiş (Resim 3-4) ve alınan endoskopik biyopsi patoloji sonucu HCC ile uyumlu olarak rapor edilmiştir (Resim 5-6). Hastanın hepatik dekompanzasyonu nedeniyle palyatif tedaviler uygulanmış ve klinik takibinde hasta kaybedilmiştir.

\section{TARTISQMA}

HCC ylllı 250.000'in üzerinde ölümden sorumlu olan ve dünya çapında en sık görülen tümörlerden biridir (1). İlerlemiş HCC'de karaciğer dışı metastazların, yaklaşık \%30-75 oranında ve genellikle akciğer, bölgesel lenf nodları, kemik ve adrenal bezlere olduğu bildirilmiştir (6). Ilerlemiş HCC'de GIS kanamaları sıklıkla portal hipertansiyona bağlı variseal kanamalar şeklinde görülmektedir. GIS'e tümör invazyonu oldukça seyrektir. Lin ve ark.'1 2237 hastanın 11 'inde $(\% 0,5)$ Gís'e HCC invazyonu bildirirken (4), Chen ve ark'1 396 hastanın 8'inde (\%2) tümör invazyonu rapor etmişlerdir (5). Her iki çalışmada da en sık GIS invazyonunun duodenum ve mide olduğu gösterilmiştir. Primer tümör saptanmasından GIS invazyonu için geçen median zaman yaklaşık 4,5 ay bulun-
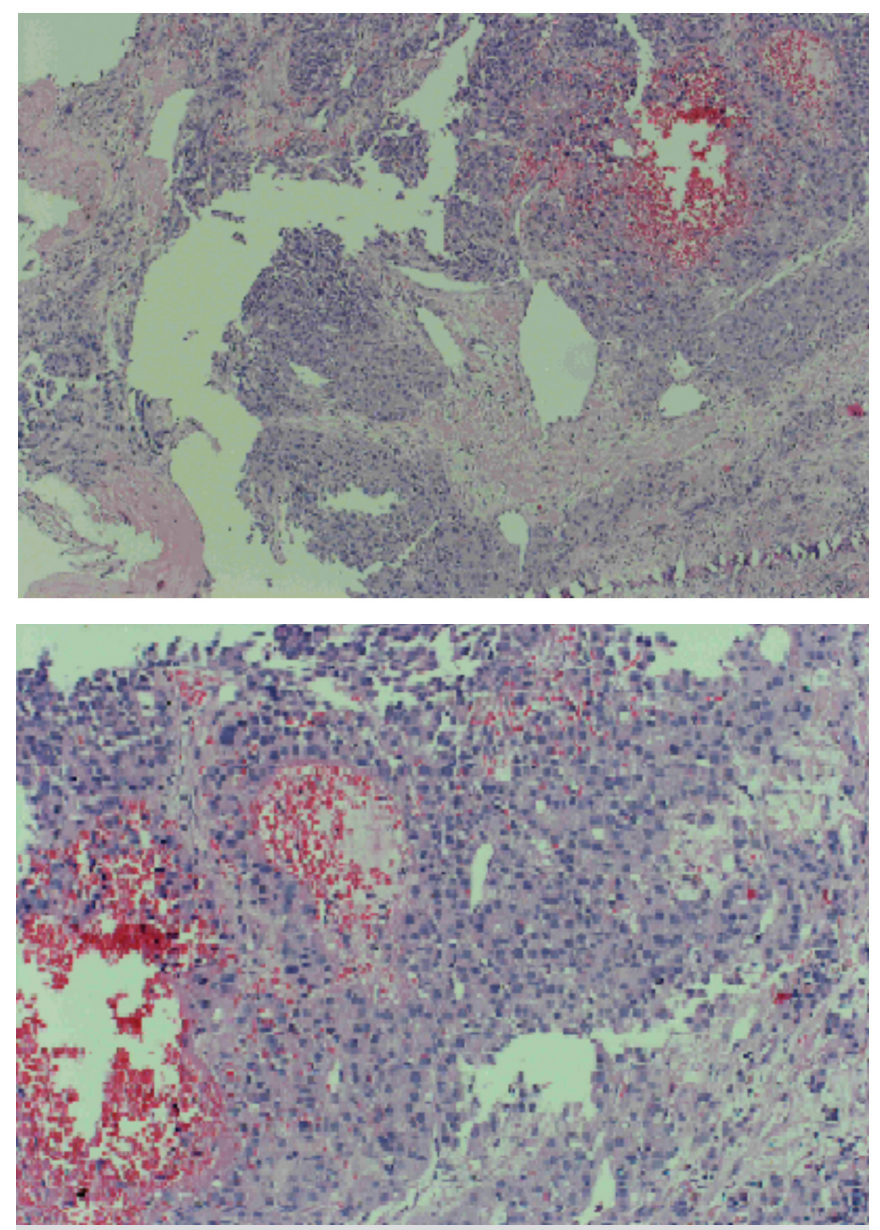

Resim 5-6. Hematoksilen eozin boyalı patoloji preparatlarında HCC'ye ait tümöral doku. 
muştur. GIS invazyonu olduğunda median sağkalım ise cerrahi yapılan hastalarda 9,7 ay, cerrahi dişı tedavilerle 3 ay, sadece destek tedavisi ile 1,2 ay olarak rapor edilmiştir (7). Iki yll önce HCC nedeniyle rezeksiyon uygulanmış ve nüks HCC'nin duodenum invazyonuna bağlı masif kanama ile başvuran bu olguda da, hepatik dekompanzasyon nedeniyle sa- dece destek tedavisi uygulanabilmiş ve 1 ay sonra hasta kaybedilmiştir

Karaciğer sirozu zemininde HCC gelişmiş hastalarda, GIS kanama bulguları varlığında, HCC'nin duodenum invazyonuna bağlı tümöral kanama olasılığı akılda tutulmalı ve fatal seyredebileceği dikkate alınmalıdır.

\section{KAYNAKLAR}

1. Ramsey WH, Wu GY. Hepatocellular carcinoma: update on diagnosis and treatment. Dig Dis 1995; 13: 81-91.

2. Carbonell N, Pauwels A, Serfaty L, et al. Improved survival after variceal bleeding in patients with cirrhosis over the past two decades. Hepatology 2004; 40: 652-9.

3. Longstreth GF. Epidemiology of hospitalization for acute upper gastrointestinal hemorrhage: a population-based study. Am J Gastroenterol 1995; 90: 206-10.

4. Lin CP, Cheng JS, Lai KH, et al. Gastrointestinal metastasis in hepatocellular carcinoma: radiological and endoscopic studies of 11 cases. J Gastroenterol Hepatol 2000; 15: 536-41.

5. Chen LT, Chen CY, Jan CM, et al. Gastrointestinal tract involvement in hepatocellular carcinoma: clinical, radiological and endoscopic studies. Endoscopy 1990; 22: 118-23.

6. El-Serag HB, Rudolph KL. Hepatocellular carcinoma: epidemiology and molecular carcinogenesis. Gastroenterology 2007; 132: 2557-76.

7. Fujii K, Nagino M, Kamiya J, et al. Complete resection of hepatocellular carcinoma with direct invasion to the stomach remnant. J Hepatobiliary Pancreat Surg 2004; 11: 441-4. 